Psychology of Language and Communication 2010, Vol. 14, No. 2

DOI: $10.2478 /$ v10057-010-0008-3

\author{
NAWOJA MIKOŁAJCZAK-MATYJA \\ Adam Mickiewicz University, Poznań
}

\title{
THE SUPERORDINATION RELATION AND THE SYMMETRY OF VERBAL ASSOCIATIONS IN SELECTED PARTS OF THE MENTAL LEXICON
}

\begin{abstract}
The paper discusses the role of the superordination relation in the semantic organization of the mental lexicon. The method of three consecutive free association tests (reactions from the previous test are stimuli in the next one, so lists of stimuli are prepared for each respondent separately) was used to determine the role of different kinds of semantic relations in building some fragments of the lexicon. A detailed semantic analysis made in 1200 recurrent (symmetrical) and non-recurrent "chains" built with associations given by 50 secondary school students (Polish language users) revealed the relative importance of the superordination relation as a factor connecting elements of the mental lexicon: the hyponymy/hyperonymy relation occurs more regularly in various lexicon parts than other paradigmatic relations.

Key words: mental lexicon, verbal associations, semantic relations, lexical relations, hyponymy
\end{abstract}

\section{Introduction}

\section{The role of hyponymy/hyperonymy relations in the mental lexicon structure}

In psycholinguistics the mental lexicon, as a part of the long-term memory, is interpreted as storage of lexical items and knowledge concerning these items or as a creative component in the processes of speech production and perception. The former interpretation forms the basis for two metaphors, namely lexicon-asdictionary and lexicon-as-thesaurus, emphasizing the fact that any lexical item, or rather any lexical entry (i.e. collection of phonemic, morphological, syntactic and semantic information concerning the lexical item), is linked to other lexical entries (Leech, 1987; Marslen-Wilson, Tyler, Waksler, \& Older, 2002; Mikołajczak-Matyja, 2008; Murphy, 2003; Wunderlich, 2006).

Address for correspondence: Nawoja Mikołajczak-Matyja, Adam Mickiewicz University, Faculty of Modern Languages and Literature, Institute of Linguistics, Al. Niepodległości 4, 61-874 Poznań, Poland. E-mail: nawomiko@amu.edu.pl 
Semantic aspects of knowledge concerning lexical items determine the semantic organization of the mental lexicon. The reality of such a semantic structure and its role in speech production and perception has been proved by much research and in numerous ways. One of the basic relations determining semantic organization between lexical items is the relation of class inclusion or the superordination relation (as between sparrow and bird), with its two aspects, symmetrical to each other, i.e. hyponymy (sparrow is a hyponym of bird) and hyperonymy (bird is a hyperonym of sparrow). Despite the lack of a precise and generally accepted definition of hyponymy/hyperonymy (for discussions concerning definitions of hyponymy see, for example, Cruse, 1995, 2000, 2002; Fellbaum, 1999; Mikołajczak-Matyja, 2008; Pogonowski, 1991) it is assumed that class inclusion is one of fundamental factors in organizing the semantic memory, mental lexicon and lexical aspects of a language. The assumption is based on results of extensive research from areas such as anthropological linguistics, semantics, psychology and psycholinguistics.

Firstly, the experiments have uncovered features of the so-called folk or natural taxonomies which are considered to be a reflection of semantic-conceptual structures of language users. Folk taxonomy is defined as "a system of monolexically labeled folk segregates related by hierarchic inclusion" (Conklin, 1962, p. 128). The main subject of experiment and observation are taxonomies concerning plants and animals, but also colors and some artifacts. Results of anthropological research (see for example Berlin, Breedlove, \& Raven, 1968, 1973, 1974) are compared and verified by psychological and psycholinguistic experiments conducted on respondents from Western cultures (see Medin \& Atran, 1999) and modified or completed by semantic analysis made by linguists (see for example Cruse, 1995; 2000; Ungerer \& Schmid, 1996). The basic problems concerning folk taxonomies are the number of levels and their status in cognitive and linguistic processes.

Secondly, the arrangement based on the hyponymy/hyperonymy relation is also a crucial characteristic of some semantic memory models. Semantic memory (a part of declarative memory) is defined as "a mental thesaurus, organized knowledge a person possesses about words and other verbal symbols, their meanings and referents..." (Tulving, 1972, p. 386), so this kind of memory system can be interpreted as being strictly related to the mental lexicon or even as containing that lexicon. Theories of semantic memory and semantic representations fall into two general classes: featural or decompositional views in which a word's meaning is represented in terms of separable aspects (features), together constituting the meaning of each word, and holistic theories, such as network models and semantic fields theory, in which a word's meaning is represented in terms of its relations to other words (Harley 2003, Vigliocco, Vinson 2007). In semantic network models the items of such a network - called nodes - are connected to each other by links which specify the relation between the linked nodes. The most common link is an ISA link (as between pig and mammal or mammal and animal), therefore a link specifying the hyponymy/hyperonymy relation (Collins \& Loftus, 1975; Collins \& Quillian, 1969; 
Quillian, 1968; see also Harley, 2003; Sowa, 2000). The crucial role of the class inclusion relation is also emphasized in other theories of semantic memory. For example, in the model proposed by Miller and Johnson-Laird the semantic memory system consists of semantic fields whose structure is determined, among other things, by the hyponymy relation (Miller \& Johnson-Laird, 1976).

Both folk taxonomies and semantic memory models, as constructs reflecting the structure of language users' knowledge, also uncover other semantic relations as factors determining this structure, i.e. cohyponymy, meronymy/holonymy (partwhole relations), the location relation, the relation of attribution etc. But connecting lexical units by the superordination relation makes the structure hierarchical and theoretically can encompass and hierarchically organize the whole of human knowledge (this problem is the subject of many philosophical considerations based on Aristotle's theory concerning categories, see Aristotle, ed. 1844).

\section{The free association test as a method of uncovering the mental lexicon structure}

There are numerous methods uncovering semantic relations between mental lexicon units. They differ from one another by whether or to what degree respondents are conscious of the existence of such relations during the experiment. Therefore, on the one hand, subjects can be conscious that the aim of the experiment is to search for specific relations. For instance, they could be told to give antonyms/ hyperonyms/hyponyms/synonyms etc. of some verbal stimuli or to name the relation between two or more stimuli. On the other hand, the relations can emerge automatically and unintentionally, in reaction to the instruction in an experiment (as in priming or semantic generalization experiments) or during natural speech production, in some types of slips of the tongue. And between these "extremes" there are many methods in which respondents can be more or less conscious of the type of relation when reacting to some stimuli, as, for example, in the methods of semantic decision or of defining lexical units.

The free association test is one of the oldest methods revealing the structure of the mental lexicon. It can be treated as being close to "the unconscious extreme" of the continuum of experiments: respondents are told to give verbal reactions to stimulus words quickly, without thinking or deliberating over them. The history of verbal association experiments indicates a possibility of interpreting their results both in terms of the language behavior characteristics of the respondents, and in terms of non-language processes which are an area of interest for psychology. The role of such experiments in contemporary science is confirmed by studies carried out over the past dozen or so years. Firstly, new association norms are developed for many languages, e.g., French (Ferrand, 2001; Ferrand \& Alario, 1998), English (Hirsh \& Tree, 2001) or Polish (Łobacz \& Mikołajczak-Matyja, 2002). Secondly, association experiments and re-developed association norms are used extensively in research on speech production and mental lexicon access and structure (see for instance 
Bock, 2002; Forster, 2002; Moss, McCormick \& Tyler, 1995), acquisition of a second language (Cieślicka-Ratajczak, 1985; Wilks \& Meara, 2002; Wolter, 2002), memory (Latour \& McKelvie, 1994), cognitive development of children (Houde, 1990), personality (Hunca-Bednarska, 1997; Johnson \& Shean, 1993; Upmanyu, Bhardwaj \& Singh, 1996), psychology of people with visual impairment (Mikołajczak-Matyja, 2004; Mikołajczak-Matyja, 2008; Wyver, Markham, \& Hlavacek, 2000) etc.

Semantic analysis of association test results - looking for semantic relations between stimulus and reaction - has a long (more than 100-year) tradition (see overview in Hörmann, 1972). It has been evident that even within the same semantic field, only some instances of a type of semantic relation are strongly associated in language users' mental lexicons, e.g., silver and gold (instance of the cohyponymy relation or category co-membership, i.e. the relation between words with a close common hyperonym) are much more strongly associated with each other than silver and brown (Harley, 2003; Moss, McCormick, \& Tyler, 2002). On the other hand, some words become associated if they tend to co-occur frequently or to be used in the same sort of contexts, even if they are not semantically related (like cheese and mouse). Thus, the strength of connections in the associative structure of the mental lexicon does not precisely reflect the strength of semantic connections between lexical items. However, some associations which can be qualified as instances of basic semantic relations appear to be very typical or even dominant (the most common) associations in tests performed on large groups of respondents. For example, in English and French association norms developed in the mid-20th century using the Kent-Rosanoff list of 100 stimulus words (the original English list and the list translated into French) there were: for the English language 13, and for the French language 10 dominant reactions related to stimuli through the superordination relation (data from my own analysis of the norms published in the article by Russell and Meseck (Russell \& Meseck, 1959)).

Association norms for the Polish language using the same Kent-Rosanoff list of 100 stimuli (translated into Polish) were developed twice: in the 1960s and the 1990s (published in works by Kurcz, 1967; Kurcz, 1976; Łobacz \& MikołajczakMatyja, 2002). The results of semantic analysis between dominant reactions and stimuli, with respect to the number of instances of basic paradigmatic semantic relations, are as follows (all associative reactions cited in the present paper are close English equivalents of the original Polish answers; stimulus words, in this and subsequent paragraphs, are cited from the original English version of the Kent-Rosanoff list):

- synonymy (example: doctor $\rightarrow$ physician), 1960s: 8, 1990s: 12,

- classical antonymy (example: black $\rightarrow$ white), 1960s: 10, 1990s: 4,

- complementary antonymy or complenymy (example: boy $\rightarrow$ girl), 1960s: 5, 1990s: 4,

- superordination relation (example: eagle $\rightarrow$ bird), 1960s: 7, 1990s: 14,

- part-whole relation (example: foot $\rightarrow$ leg), 1960s: 3, 1990s: 9, 
- individual-set or set membership relation (example: city $\rightarrow$ Warsaw), 1960s: 2, 1990s: 2,

- cohyponymy relation (chair $\rightarrow$ table), 1960s: 4, 1990s: 4 .

The type of relation between dominant reaction and stimulus depends, to a certain degree, on the semantic field the stimulus belongs to. Hence, for example, instances of classical antonymy are typical mostly for adjectival stimuli, complementary antonymy is characteristic for names of people (as man, woman, boy), synonymy for some abstract nouns, such as names of states, situations or emotions etc. Instances of the superordination relation seem to appear in many semantic fields (especially in the norms from the 1990s), to be precise for names of plants and animals, people and professions, food and beverages and geometrical figures (all quantitative and qualitative data concerning Polish norms come from Łobacz \& Mikołajczak-Matyja, 2002).

An analysis of the associative norms reveals "interpersonal" and "mean" typicality of semantic relations as factors determining the structure of the "average" mental lexicon of a language community. And in order to make it possible to examine the strength of given semantic associations in building the individual mental lexicon, another type of experiment is needed. The simplest method is a free association test repeated twice or more times on the same respondent (or the same group of respondents) and by using the same list of stimuli. But there is also another possibility: an experiment consisting of two or more free association tests performed on the same respondent, in which the list of stimuli for a subsequent test is always constructed of the reactions given by the respondent in the previous test (with a large time interval between tests). A method like this makes it possible to reveal an additional and very interesting aspect of the mental lexicon structure: symmetry of associations. Thus, for example, if a respondent gives lexical item $\mathrm{Y}$ as a free association (reaction) to lexical item $\mathrm{X}$ (stimulus) and then, in the second test, gives $\mathrm{X}$ as a reaction to $\mathrm{Y}$, used this time as a stimulus, the association between $\mathrm{X}$ and $\mathrm{Y}$ is symmetrical and can be interpreted as a strong mutual connection in the respondent's mental lexicon. This method reveals an "architecture" of the mental lexicon as consisting of fragments built of symmetrical associations and fragments built of asymmetrical ones (where $\mathrm{X}$ elicits $\mathrm{Y}$ as a reaction, and $\mathrm{Y}$ as a stimulus elicits $\mathrm{Z}$ etc.). The more tests in the experiment, the larger the lexicon fragments that are uncovered (where there are not any symmetrical associations) or the stronger the connections between lexical items that are revealed (where there are symmetrical associations and X elicits $\mathrm{Y}, \mathrm{Y}$ elicits $\mathrm{X}$, then $\mathrm{X}$ elicits $\mathrm{Y}$ again etc.). Stimuli and reactions from succeeding tests of such an experiment produce a kind of "chain" of elements whose structure depends on whether there exist symmetrical associations between elements or not.

The main objective of the experiment presented in the subsequent paragraphs is to determine the role of the class inclusion relation (hyponymy/hyperonymy or superordination relation), as compared with other paradigmatic relations, in the 
associative structure of individual mental lexicons of Polish language users. The method of three free association tests with a list of stimuli prepared for every respondent separately makes it possible to determine the role of the superordination relation in associatively symmetrical and asymmetrical fragments of the lexicon.

\section{Method}

The experiment consisted of three free association tests. The respondents, 50 secondary school students aged 18-19, were asked to give the first word that occurred to them when reading a word-stimulus. The stimulus words were presented in three lists:

- The first list was the same for all respondents. It was the Polish version of the Kent-Rosanoff list of 100 stimulus words (nouns, verbs and adjectives). But the real experimental material consisted of only 24 nouns and adjectives (S1) belonging to 8 different lexical fields, concerning living beings, non-living objects, social roles, feelings and sensations, specifically:

1. People: woman, man, girl

2. Animals: sheep, spider, lion

3. Tools: needle, hammer, scissors

4. Furniture: table, chair, bed

5. Emotions: anger, joy, afraid

6. Professions: priest, soldier, king

7. Tastes: sweet, sour, bitter

8. Colors: yellow, red, white

The whole Kent-Rosanoff test was used in order to minimize the possibility of the set of reactions (R1) given by a respondent to the real 24 stimuli words being stored in his/her long-term memory.

The second list was prepared for each respondent separately and consisted of 24 stimulus words (S2). These stimulus words were reactions given by the respondent to each stimulus from the first list. Thus, $\mathrm{R} 1=\mathrm{S} 2$.

The third list, again, was prepared for each and every respondent separately and consisted of 24 stimulus words (S3). These stimulus words were reactions given by the respondent to the stimuli from the second list. Thus, $\mathrm{R} 2=\mathrm{S} 3$.

Consequently, 24 chains of the type: $\mathrm{S} 1 \rightarrow \mathrm{R} 1=\mathrm{S} 2 \rightarrow \mathrm{R} 2=\mathrm{S} 3 \rightarrow \mathrm{R} 3$ were obtained for every respondent, for instance: (S1) man $\rightarrow(\mathrm{R} 1=\mathrm{S} 2)$ father $\rightarrow(\mathrm{R} 2=\mathrm{S} 3)$ family $\rightarrow$ (R3) mother.

The experiment was a written one. It consisted of three stages (i.e. three association tests), performed at four-week intervals. In each stage the respondents were given a questionnaire comprising instructions and a list of stimuli. They were not informed that the last two lists consisted of their own reactions from previous tests. It was assumed that every stage would be treated by the respondents as a new experimental situation, totally disconnected from the previous ones. 


\section{Results}

\section{Types of chains}

Fifty chains were obtained for each of the 24 nouns (for $24 \mathrm{~S} 1 \mathrm{~s}$ ). The corpus of 1200 chains was classified into five structural types on the basis of recurrence of chain elements. In order to make the structural types distinctive, the letters A, B, C, D were assigned (in alphabetic order) to the elements of a chain. If all the elements of a chain were different lexical units, a different letter was assigned to each element. If any two elements of a chain were the same lexical units (were recurrent), the same letter was assigned to both of them. As a result the following types of chains were obtained:

If all the elements of a given chain are different lexical units (no recurrent elements, i.e. no symmetrical associations between elements were found), the chain is of the non-recurrent type $\mathrm{ABCD}: \mathrm{S} 1: \mathrm{A} \rightarrow \mathrm{R} 1=\mathrm{S} 2: \mathrm{B} \rightarrow \mathrm{R} 2=\mathrm{S} 3: \mathrm{C} \rightarrow \mathrm{R} 3: \mathrm{D}$.

Example: sour $\rightarrow$ lemon $\rightarrow$ tea $\rightarrow$ coffee; see also the example shown in the previous paragraph.

If any two elements of a chain are the same lexical units (recurrent elements), the chain is of one of four recurrent types:

- ABAC: the first element (S1) and the third one (R2=S3) are the same lexical units (i.e. symmetrical association between $\mathrm{A}$ and $\mathrm{B}$ occurred).

Example: woman $\rightarrow$ man $\rightarrow$ woman $\rightarrow$ child.

- $\mathrm{ABCB}$ : the second element (R1=S2) and the fourth (last) element (R3) are the same lexical units (i.e. symmetrical association between B and C occurred). Example: hammer $\rightarrow$ nail $\rightarrow$ board $\rightarrow$ nail.

- ABCA: The first element (S1) and the last one (R3) are the same lexical units (no direct symmetrical association between two elements occurred, but a kind of "indirect symmetry", i.e. the first stimulus is elicited as a reaction through the mediation of the two middle elements).

Example: needle $\rightarrow$ thread $\rightarrow$ sewing $\rightarrow$ needle.

- ABAB: the first element (S1) and the third element $(\mathrm{R} 2=\mathrm{S} 3)$ are the same lexical units and the second element $(\mathrm{R} 1=\mathrm{S} 2)$ and the last element $(\mathrm{R} 3)$ are the same lexical units (double symmetrical association between A and B occurred).

Example: white $\rightarrow$ black $\rightarrow$ white $\rightarrow$ black.

Elements recognized as the same lexical items were not only identical elements, but also elements with different grammatical number (like nail and nails), of different grammatical gender (this concerns adjectives, Polish example: ostre and ostry) and some diminutive and basic forms (Polish example: nitka and nic).

Table 1 presents the number of chains of all types obtained for the whole material.

The number of non-recurrent and recurrent chains for the whole material is similar (respectively: 622 and 578 chains or $52 \%$ and $48 \%$ for the corpus of 1200 
Table 1: Number of chains of 5 types

\begin{tabular}{lccccc}
\hline \multirow{2}{*}{ Lexical field } & \multicolumn{5}{c}{ Type of chain } \\
\cline { 2 - 6 } & ABCD & ABAC & ABCB & ABCA & ABAB \\
\hline People & 64 & 18 & 32 & 5 & 31 \\
Animals & 91 & 12 & 35 & 2 & 10 \\
Tools & 75 & 13 & 19 & 1 & 42 \\
Furniture & 77 & 15 & 30 & 7 & 21 \\
Emotions & 79 & 14 & 36 & 6 & 15 \\
Professions & 71 & 23 & 28 & 5 & 23 \\
Tastes & 87 & 7 & 40 & 0 & 16 \\
Colors & 78 & 14 & 44 & 0 & 14 \\
Total & 622 & 116 & 264 & 26 & 172 \\
\hline
\end{tabular}

chains). Chains of the $\mathrm{ABCB}$ type are the most frequent among the recurrent chains (almost $50 \%$ of recurrent chains and more than $20 \%$ of all chains) while chains of the $\mathrm{ABCA}$ type are the least frequent (only about $2 \%$ of all chains).

The symmetry of association between two lexical items, interpreted as the situation when one word evokes another word and is directly evoked by it, is quite typical: recurrent chains of the types $\mathrm{ABCB}, \mathrm{ABAC}$ and $\mathrm{ABAB}$ make up $46 \%$ of all 1200 chains.

The domination of $\mathrm{ABCB}$ chains among recurrent chains is typical for seven fields, with the strongest domination in the adjectival fields Tastes and Colors. Only in the field Tools do chains of the $A B A B$ type outnumber $A B C B$ chains. $A B C A$ chains were the least frequent type of recurrent chains for all 8 fields. No chain of this type was obtained for the adjectival fields.

Table 2 shows the proportions of recurrent and non-recurrent chains for the 8 lexical fields.

The proportions shown in Table 2 are quite similar for all 8 fields, and even very similar for the fields: Tools, Furniture, Emotions, Colors and Professions. The percentage for the two general types of chain - recurrent and non-recurrent - is almost the same in these five fields. The number of recurrent chains is higher than the number of non-recurrent chains only in the fields People and Professions.

\section{Identical chains}

Some of the chains obtained from different respondents are identical, i.e. built of the same elements in the same positions, in spite of the fact that the experiment consisted of three tests and that two of them were constructed for each and every respondent separately. Such identical chains can be interpreted as evidence of a high similarity of the associative structure for mental lexicons in the minds of different language users. 
Table 2: Proportions of recurrent and non-recurrent chains

\begin{tabular}{lcc}
\hline \multirow{2}{*}{ Lexical Field } & \multicolumn{2}{c}{ Type of chain } \\
\cline { 2 - 3 } & Non-recurrent & Recurrent \\
\hline People & $43 \%$ & $57 \%$ \\
Animals & $61 \%$ & $39 \%$ \\
Tools & $50 \%$ & $50 \%$ \\
Furniture & $52 \%$ & $48 \%$ \\
Emotions & $53 \%$ & $47 \%$ \\
Professions & $47 \%$ & $53 \%$ \\
Tastes & $58 \%$ & $42 \%$ \\
Colors & $52 \%$ & $48 \%$ \\
\hline
\end{tabular}

Identical chains were found for all stimuli. Most of the identical chains are of the $A B A B$ type. Identical chains of this type are found for 21 stimuli and they are often built from the responses of more than two respondents. Identical chains of the $A B C B$ type were found for 13 stimuli, of the $A B C D$ type - for 11 stimuli and of the ABAC type for 6 stimuli. Most of them are given by no more than two respondents. No identical chains of the ABCA type were found in the material.

All the chains given by a minimum of 5 respondents (minimum $10 \%$ of the group) are cited below (number of respondents in brackets). All but one (the last one) are of the ABAB type.

$$
\begin{aligned}
& \text { needle } \rightarrow \text { thread } \rightarrow \text { needle } \rightarrow \text { thread }(20) \\
& \text { hammer } \rightarrow \text { nail } \rightarrow \text { hammer } \rightarrow \text { nail }(16) \\
& \text { girl } \rightarrow \text { boy } \rightarrow \text { girl } \rightarrow \text { boy }(7) \\
& \text { anger } \rightarrow \text { wrath } \rightarrow \text { anger } \rightarrow \text { wrath }(6) \\
& \text { chair } \rightarrow \text { table } \rightarrow \text { chair } \rightarrow \text { table }(5) \\
& \text { table } \rightarrow \text { chair } \rightarrow \text { table } \rightarrow \text { chair }(5) \\
& \text { priest } \rightarrow \text { cassock } \rightarrow \text { priest } \rightarrow \text { cassock }(5) \\
& \text { sweet } \rightarrow \text { bitter } \rightarrow \text { sweet } \rightarrow \text { bitter }(5) \\
& \text { bitter } \rightarrow \text { sweet } \rightarrow \text { bitter } \rightarrow \text { sweet }(5) \\
& \text { white } \rightarrow \text { black } \rightarrow \text { white } \rightarrow \text { black }(5) \\
& \text { afraid } \rightarrow \text { anxiety } \rightarrow \text { fear } \rightarrow \text { anxiety }(5)
\end{aligned}
$$

\section{Semantic relations in recurrent chains}

A detailed content analysis revealed semantic relations between immediately neighboring elements of recurrent chains. Only basic relations between words of the same syntactic category (paradigmatic relations) were taken into consideration, that is, synonymy, classical antonymy, complementary antonymy and converse antonymy, hyponymy/hyperonymy (superordination relations), meronymy/ holonymy (part-whole relations), cohyponymy, the individual-set relation (set 
Table 3. Basic semantic relations in recurrent chains

\begin{tabular}{|c|c|c|c|c|c|c|c|c|}
\hline \multirow[t]{2}{*}{$\overline{\text { Stimulus }}$} & \multicolumn{8}{|c|}{ Number of relations } \\
\hline & syn & ant & compl & hypon & hyper & mer & hol & coh \\
\hline \multicolumn{9}{|l|}{ People } \\
\hline woman & $5 / 8$ & $1 / 2$ & $12 / 25$ & $10 / 13$ & $6 / 6$ & $2 / 2$ & 0 & $4 / 4$ \\
\hline $\operatorname{man}$ & $1 / 3$ & $1 / 2$ & $16 / 41$ & $13 / 19$ & $10 / 12$ & $1 / 1$ & $1 / 1$ & $0 / 0$ \\
\hline girl & $6 / 9$ & $0 / 0$ & $12 / 30$ & $9 / 10$ & $12 / 14$ & $1 / 1$ & $0 / 0$ & $1 / 1$ \\
\hline subtotal & $12 / 20$ & $2 / 4$ & $40 / 96$ & $32 / 42$ & $28 / 32$ & $4 / 4$ & $1 / 1$ & $5 / 5$ \\
\hline \multicolumn{9}{|l|}{ Animals } \\
\hline sheep & $0 / 0$ & $0 / 0$ & $1 / 2$ & $3 / 3$ & $3 / 6$ & $9 / 15$ & $8 / 8$ & $2 / 4$ \\
\hline spider & $3 / 6$ & $0 / 0$ & $1 / 2$ & $8 / 8$ & $8 / 8$ & $1 / 1$ & $0 / 0$ & $7 / 8$ \\
\hline lion & $2 / 3$ & $0 / 0$ & $1 / 2$ & $6 / 6$ & $7 / 10$ & $3 / 5$ & $2 / 2$ & $1 / 3$ \\
\hline subtotal & $5 / 9$ & $0 / 0$ & $3 / 6$ & $17 / 17$ & $18 / 24$ & $13 / 21$ & $10 / 10$ & $10 / 15$ \\
\hline \multicolumn{9}{|l|}{ Tools } \\
\hline needle & $1 / 2$ & $0 / 0$ & $0 / 0$ & $0 / 0$ & $0 / 0$ & $1 / 1$ & $1 / 1$ & $1 / 1$ \\
\hline hammer & $3 / 6$ & $0 / 0$ & $0 / 0$ & $1 / 1$ & $4 / 4$ & $1 / 2$ & $1 / 1$ & $1 / 3$ \\
\hline scissors & $0 / 0$ & $0 / 0$ & $0 / 0$ & $1 / 1$ & $1 / 1$ & $2 / 2$ & $1 / 1$ & $1 / 1$ \\
\hline subtotal & $4 / 8$ & $0 / 0$ & $0 / 0$ & $2 / 2$ & $5 / 5$ & $4 / 5$ & $3 / 3$ & $3 / 5$ \\
\hline \multicolumn{9}{|c|}{ Furniture } \\
\hline table & $0 / 0$ & $0 / 0$ & $0 / 0$ & $8 / 8$ & $9 / 12$ & $7 / 11$ & $7 / 7$ & $15 / 28$ \\
\hline chair & $0 / 0$ & $0 / 0$ & $0 / 0$ & $11 / 11$ & $11 / 19$ & $3 / 5$ & $3 / 3$ & $17 / 35$ \\
\hline bed & $5 / 9$ & $0 / 0$ & $0 / 0$ & $2 / 2$ & $3 / 4$ & $1 / 1$ & $0 / 0$ & $1 / 1$ \\
\hline subtotal & $5 / 9$ & $0 / 0$ & $0 / 0$ & $21 / 21$ & $23 / 35$ & $11 / 17$ & $10 / 10$ & $33 / 64$ \\
\hline \multicolumn{9}{|c|}{ Emotions } \\
\hline anger & $12 / 29$ & $0 / 0$ & $0 / 0$ & $2 / 2$ & $2 / 2$ & $0 / 0$ & $0 / 0$ & $10 / 18$ \\
\hline joy & $4 / 9$ & $5 / 8$ & $0 / 0$ & $1 / 1$ & $1 / 1$ & $0 / 0$ & $0 / 0$ & $7 / 14$ \\
\hline afraid & $26 / 69$ & $0 / 0$ & $0 / 0$ & $0 / 0$ & $0 / 0$ & $0 / 0$ & $0 / 0$ & $0 / 0$ \\
\hline subtotal & $42 / 107$ & $5 / 8$ & $0 / 0$ & $3 / 3$ & $3 / 3$ & $0 / 0$ & $0 / 0$ & $17 / 32$ \\
\hline \multicolumn{9}{|c|}{ Professions } \\
\hline priest & $1 / 2$ & $0 / 0$ & $0 / 0$ & $8 / 9$ & $9 / 12$ & $6 / 6$ & $15 / 21$ & $3 / 5$ \\
\hline soldier & $2 / 3$ & $0 / 0$ & $0 / 0$ & $1 / 1$ & $1 / 1$ & $5 / 5$ & $9 / 14$ & $0 / 0$ \\
\hline king & $3 / 6$ & $0 / 0$ & $1 / 2$ & $10 / 10$ & $12 / 16$ & $1 / 1$ & $2 / 2$ & $1 / 2$ \\
\hline subtotal & $6 / 11$ & $0 / 0$ & $1 / 2$ & $19 / 20$ & $22 / 29$ & $12 / 12$ & $26 / 37$ & $4 / 7$ \\
\hline \multicolumn{9}{|l|}{ Tastes } \\
\hline sweet & $0 / 0$ & $7 / 19$ & $0 / 0$ & $10 / 10$ & $10 / 10$ & $3 / 3$ & $3 / 3$ & $0 / 0$ \\
\hline sour & $1 / 2$ & $6 / 13$ & $0 / 0$ & $4 / 4$ & $4 / 4$ & $2 / 2$ & $2 / 2$ & $0 / 0$ \\
\hline bitter & $3 / 6$ & $7 / 20$ & $0 / 0$ & $1 / 1$ & $1 / 1$ & $1 / 1$ & $1 / 1$ & $0 / 0$ \\
\hline subtotal & $4 / 8$ & $20 / 52$ & $0 / 0$ & $15 / 15$ & $15 / 15$ & $6 / 6$ & $6 / 6$ & $0 / 0$ \\
\hline \multicolumn{9}{|l|}{ Colors } \\
\hline yellow & $0 / 0$ & $0 / 0$ & $0 / 0$ & $3 / 3$ & $3 / 3$ & $0 / 0$ & $0 / 0$ & $0 / 0$ \\
\hline red & $0 / 0$ & $0 / 0$ & $0 / 0$ & $2 / 2$ & $2 / 2$ & $2 / 2$ & $2 / 2$ & $3 / 5$ \\
\hline white & $0 / 0$ & $7 / 18$ & $0 / 0$ & $1 / 1$ & $1 / 1$ & $2 / 2$ & $2 / 2$ & $0 / 0$ \\
\hline subtotal & $0 / 0$ & $7 / 18$ & $0 / 0$ & $6 / 6$ & $6 / 6$ & $4 / 4$ & $4 / 4$ & $3 / 5$ \\
\hline Total: & $78 / 172$ & $34 / 82$ & $44 / 104$ & $115 / 126$ & $120 / 149$ & $54 / 69$ & $60 / 71$ & $75 / 133$ \\
\hline
\end{tabular}


membership) and also, as an exception, one relation between noun and adjective: quasi-hyponymy/hyperonymy between more specific adjectives such as sweet or yellow and more general abstract nouns such as, respectively, taste and color (cf. Lyons 1977). In the case of asymmetrical relations, such as superordination and part-whole relations, the relation between two elements was interpreted as follows:

- when the next element was a hyperonym of the previous one, e.g., fly $\rightarrow$ insect: hyperonymy,

- when the next element was a hyponym of the previous one, e.g., animal $\rightarrow$ dog: hyponymy,

- when the next element was a holonym of the previous one, e.g., table top $\rightarrow$ table: holonymy,

- when the next element was a meronym of the previous one, e.g., spider $\rightarrow$ leg: meronymy.

In order to objectify the author's analysis and annotation of relations within the chains, the meanings of the stimuli and reactions given in contemporary Polish language dictionaries were taken into account. Table 3 presents the numbers of relations for the most common types: synonymy (syn), classical (ant) and complementary (compl) antonymy, hyponymy (hypon), hyperonymy (hyper), meronymy (mer), holonymy (hol) and cohyponymy (coh). The notation included in a cell should be interpreted as follows: the number of recurrent chains for which at least one instance of a relation was found / sum of instances of the relation in these chains. Examples:

- 5/8 synonyms for the stimulus woman: in 5 chains 8 instances (in total) of the synonymy relation were found,

- 1/3 synonyms for the stimulus man: 3 instances of synonymy were found, all in the same chain.

The number of relations of a given type depends on the semantic field. Accordingly, complementary relations are characteristic mostly for stimuli belonging to People, classical antonymy for Tastes, synonyms for Emotions, cohyponyms for Furniture. Meronymy and holonymy occur sometimes for names of Professions, Furniture and Animals.

Hyponymy and hyperonymy are characteristic mostly for People and, to a lesser degree, for Furniture, Animals and Professions. The total sums of recurrent chains in which hyponymy and hyperonymy were found are the highest, much higher than for any other type of relation (see the last row of Table 3). At least one hyperonymy relation was found in 120 chains, thus in more than $20 \%$ of all the recurrent chains (578) and in $10 \%$ of the whole corpus of data (of 1200 chains). The proportions for the hyponymy relation are very similar (115 in the corpus of 578 and of 1200). Synonymy was found in only 78 chains and the sums for the other relations are even lower. Moreover, only hyperonymy and hyponymy relations appear for all 8 semantic fields whereas other relations appear in chains obtained for 3 to 7 fields which were taken into consideration. In fact, no 
Table 4. Superordination (sup) and part-whole (pw) relations in recurrent chains

\begin{tabular}{|c|c|c|c|c|c|}
\hline \multirow{2}{*}{ Stimulus } & \multicolumn{2}{|c|}{ Number } & \multirow{2}{*}{ Stimulus } & \multicolumn{2}{|c|}{ Number } \\
\hline & sup & pw & & sup & pw \\
\hline People & & & Emotions & & \\
\hline woman & $10 / 19$ & $2 / 2$ & anger & $2 / 4$ & $0 / 0$ \\
\hline man & $13 / 31$ & $1 / 2$ & joy & $1 / 2$ & $0 / 0$ \\
\hline girl & $12 / 24$ & $1 / 1$ & afraid & $0 / 0$ & $0 / 0$ \\
\hline subtotal & $35 / 74$ & $4 / 5$ & subtotal & $3 / 6$ & $0 / 0$ \\
\hline Animals & & & Professions & & \\
\hline sheep & $3 / 9$ & $9 / 23$ & priest & $10 / 21$ & $15 / 27$ \\
\hline spider & $9 / 16$ & $1 / 1$ & soldier & $1 / 2$ & $9 / 19$ \\
\hline lion & $7 / 16$ & $3 / 7$ & king & $13 / 26$ & $2 / 3$ \\
\hline subtotal & $19 / 41$ & $13 / 31$ & subtotal & $24 / 49$ & $26 / 49$ \\
\hline Tools & & & Tastes & & \\
\hline needle & $0 / 0$ & $1 / 2$ & sweet & $10 / 20$ & $3 / 6$ \\
\hline hammer & $4 / 5$ & $1 / 3$ & sour & $4 / 8$ & $2 / 4$ \\
\hline scissors & $1 / 2$ & $2 / 3$ & bitter & $1 / 2$ & $1 / 2$ \\
\hline subtotal & $5 / 7$ & $4 / 8$ & subtotal & $15 / 30$ & $6 / 12$ \\
\hline Furniture & & & Colors & & \\
\hline table & $9 / 20$ & $7 / 18$ & yellow & $3 / 6$ & $0 / 0$ \\
\hline chair & $11 / 30$ & $3 / 8$ & red & $2 / 4$ & $2 / 4$ \\
\hline bed & $3 / 6$ & $1 / 1$ & white & $1 / 2$ & $2 / 4$ \\
\hline subtotal & $23 / 56$ & $11 / 27$ & subtotal & $6 / 12$ & $4 / 8$ \\
\hline
\end{tabular}

Total: Sup: 130/275 PW: 68/140

hyponymy relation was found only for 2 out of 24 stimuli and the same is true for the hyperonymy relation.

However, as far as the total number of instances for relations of a given type is concerned, the results of the comparison are a little bit different: the total sum of instances for the synonymy relation is the highest (172), and the total sum of cohyponymy relations (133) is also higher than the sum of hyponymy relations (126, see the last row of Table 3). But statistical analysis using the Mann-Whitney U-test (the distributions of data are not normal, as verified by means of the Shapiro-Wilk test) showed that differences between data (numbers of instances) obtained for the pairs of relations: hyponymy and cohyponymy, hyponymy and synonymy, hyperonymy and cohyponymy, hyperonymy and synonymy, are not statistically significant, while differences between data obtained for the pairs: hyponymy and antonymy, hyponymy and complenymy, hyponymy and 
meronymy, hyponymy and holonymy, hyperonymy and antonymy, hyperonymy and complenymy, hyperonymy and holonymy, are statistically significant (at 5\% significance level).

Moreover, both synonymy and cohyponymy are symmetrical relations, unlike hyponymy and hyperonymy (and unlike meronymy and holonymy), so, for example, in one chain of the ABAB type: anger $\rightarrow$ wrath $\rightarrow$ anger $\rightarrow$ wrath there are 3 instances of synonymy relations while in another chain of the same type: king $\rightarrow$ ruler $\rightarrow$ king $\rightarrow$ ruler there are 2 instances of hyperonymy and 1 instance of hyponymy. Therefore, if hyponymy and hyperonymy were interpreted as two complementary aspects of the same superordination relation (e.g., the relation between lion and animal) and their instances added, the image would change. Table 4 presents such modified sums for the hyponymy/hyperonymy relations and, for comparison, the meronymy/holonymy relations (notations as in Table 3).

The total sum of instances for the superordination relation (275) is much higher than the sum obtained for the synonymy or cohyponymy relations. Differences between data (number of instances) obtained for the superordination relation and for any other type of relation (i.e. synonymy, antonymy, complenymy, cohyponymy, part-whole relation) are statistically significant (as measured using the U-test). And a comparison of subtotals shows that although the subtotals for the superordination relation are higher than the subtotals for any other relation only in the Professions and Animals fields, relatively many instances of class inclusion appear also for some other fields. Hence, it can be said that while some semantic relations are common for the structure of given semantic fields (for example, synonymy for Emotions, complenymy for People, cohyponymy for Furniture and antonymy for Tastes), the superordination relation is a rather typical tool for connecting units in various parts of the mental lexicon.

The total number of recurrent chains for which at least one superordination relation was found (130) is not the exact sum obtained for hyponymy and hyperonymy when analyzed separately (115 and 120 respectively) because relations of both types appear in many chains. Nevertheless, this number is higher than the numbers obtained for any other type of relation.

The relative dominance of the superordination relation and its typicality as a factor determining the structure of different parts of the mental lexicon is even more visible when quasi-hyperonymy and quasi-hyponymy are also taken into consideration. The results obtained for these relations are (notations as in Tables 3 and 4): for quasi-hyponymy 6/6, for quasi-hyperonymy 14/19 and 14/25 for both (for the quasi-superordination relation as a whole).

Only a few instances of converse antonymy (as between mother and child) and individual-set relation (as in king $\rightarrow$ Bolestaw Chrobry) were found in recurrent chains. The respective totals are: for the converse relation 3/6 (notations as in Tables 3 and 4) (only in chains for the stimuli woman, priest and king) and for the individual-set relation also 3/6 (only in chains for the stimuli woman and king). 
Table 5: Number of chains with strong (repeated) relations between their elements

\begin{tabular}{|c|c|c|c|c|c|c|c|c|c|c|c|c|c|c|c|c|c|c|}
\hline \multirow{3}{*}{$\begin{array}{l}\text { Lexical } \\
\text { Field }\end{array}$} & \multicolumn{18}{|c|}{ Number of chains } \\
\hline & \multicolumn{6}{|c|}{$\mathrm{ABAB}$} & \multicolumn{6}{|c|}{$\mathrm{ABAC}$} & \multicolumn{6}{|c|}{$\mathrm{ABCB}$} \\
\hline & syn & ant & com & sup & pw & $\mathrm{coh}$ & syn & ant & com & sup & pw & $\operatorname{coh}$ & syn & ant & com & sup & pw & coh \\
\hline People & 1 & 0 & 24 & 5 & 0 & 0 & 1 & 0 & 5 & 10 & 0 & 0 & 4 & 2 & 3 & 9 & 1 & 0 \\
\hline Animals & 0 & 0 & 0 & 0 & 2 & 2 & 0 & 0 & 1 & 3 & 2 & 0 & 4 & 0 & 2 & 13 & 6 & 0 \\
\hline Tools & 0 & 0 & 0 & 0 & 0 & 0 & 1 & 0 & 0 & 1 & 1 & 0 & 3 & 0 & 0 & 1 & 2 & 1 \\
\hline Furniture & 0 & 0 & 0 & 6 & 3 & 11 & 0 & 0 & 0 & 3 & 2 & 3 & 4 & 0 & 0 & 11 & 4 & 1 \\
\hline Emotions & 9 & 0 & 0 & 0 & 0 & 3 & 8 & 0 & 0 & 0 & 0 & 5 & 14 & 3 & 0 & 3 & 0 & 2 \\
\hline Professions & 1 & 0 & 0 & 6 & 6 & 0 & 1 & 0 & 1 & 7 & 2 & 2 & 3 & 0 & 0 & 4 & 4 & 1 \\
\hline Tastes & 0 & 10 & 0 & 0 & 0 & 0 & 0 & 3 & 0 & 0 & 0 & 0 & 4 & 4 & 0 & 15 & 6 & 0 \\
\hline Colors & 0 & 5 & 0 & 9 & 0 & 1 & 0 & 1 & 0 & 0 & 0 & 0 & 0 & 3 & 0 & 6 & 4 & 0 \\
\hline Total & 11 & 15 & 24 & 17 & 11 & 17 & 11 & 4 & 7 & 24 & 7 & 10 & 36 & 9 & 5 & 62 & 27 & 5 \\
\hline
\end{tabular}

Only basic paradigmatic semantic relations were taken into consideration in the analysis presented here. But in order to make the image of recurrent chains more complete, it might be worthwhile to add some information concerning other relations typical for chains obtained in the experiment. Firstly, the relation of attribution is typical for many chains, especially for chains of "adjective fields": Colors (as between white and snow) and Tastes (as between sweet and sugar) and for chains of the Profession field (as between battledress and soldier). And if relations like that between cry and anger were interpreted as attributive, we could say that this type of relation is typical also for the field of Emotions. Secondly, sometimes stimuli and reactions are associated through a function relation (as in the case of needle and sew or sewing) or through some of its results such as co-appearance (as in the case of needle and thread), most often in chains for artifacts fields: Tools and Furniture. Lastly, the location relation (as between furniture and room) is represented in some chains.

It can be assumed that the strongest associations revealed in the experiment consisting of 3 tests are manifested in relations between elements of $A B A B$ chains when one and the same association appears three times, bi-directionally (e.g., between woman and man in the chain woman $\rightarrow$ man $\rightarrow$ woman $\rightarrow$ man). Table 5 shows the numbers of $\mathrm{ABAB}$ chains constructed by means of basic paradigmatic relations.

But also symmetrical (bidirectional) associations in $\mathrm{ABA}$ as parts of $\mathrm{ABAC}$ chains and in $\mathrm{BCB}$ as parts of $\mathrm{ABCB}$ chains can be interpreted as rather strong for the mental lexicon of a given respondent: in such cases a particular relation connecting two lexical units appears twice (e.g., between animal and mammal in the chain lion $\rightarrow$ animal $\rightarrow$ mammal $\rightarrow$ animal). Accordingly, Table 5 shows 
the number of $\mathrm{ABAC}$ and $\mathrm{ABCB}$ chains in which the $\mathrm{ABA}$ and $\mathrm{BCB}$ parts were constructed by means of basic paradigmatic relations.

As far as $\mathrm{ABAB}$ chains are concerned, the highest total was obtained for chains built by means of complenymy. However, the superordination relation is the tool of constructing at least $5 \mathrm{ABAB}$ chains for 4 fields while other relations reach this level of commonality only for one or two fields: synonymy appears to be the typical relation building $\mathrm{ABAB}$ chains for the field of Emotions, antonymy for adjective fields (Tastes and Colors), complenymy for People, the part-whole relation for Professions and cohyponymy for Furniture. The ABA parts of ABAC chains are built by means of hyponymy/hyperonymy rather than any other type of basic semantic relation: the total (included in the last row of Table 5) as well as the number of fields for which hyponymy/hyperonymy build the ABA parts is the highest. For the $\mathrm{BCB}$ parts of $\mathrm{ABCB}$ chains the domination of superordination relations is even stronger and in most cases reaches statistical significance, as measured using the U-test or T-test (for two relations the distributions of data are normal, as verified by the Shapiro-Wilk test). Only the difference between superordination and synonymy does not reach the $5 \%$ significance level.

\section{Semantic relations in non-recurrent chains}

The performed content analysis uncovered basic semantic relations between immediately neighboring elements of non-recurrent chains (ABCD chains). Table 6 presents the numbers of relations of the most common types (relations and notations as in Table 3).

The number of relations of a given type depends on the semantic field. This tendency is not as strong as in the case of recurrent chains but the data included in Table 6 shows that the synonymy relation is characteristic mostly for stimuli belonging to the field of Emotions, cohyponymy and meronymy for Animals, complenymy for People, holonymy for Professions while hyponymy and hyperonymy are characteristic mostly for Tastes. The total sum of non-recurrent chains in which hyperonymy was found is the highest: at least one hyperonymy relation was found in 120 chains, so in almost $20 \%$ of all non-recurrent chains (622) and $10 \%$ of the whole corpus of data (of 1200 chains). The numbers presented in Table 6 show that most relations taken into consideration appear more regularly across the experimental material, as compared to the data concerning recurrent chains (see Table 3). However, hyperonymy relations appear in at least 10 non-recurrent chains for 6 out of the 8 fields and the same is true for hyponymy but not for other relations: meronymy appears in a minimum of 10 chains for 5 fields, cohyponymy for 4 fields, holonymy for 3 fields, synonymy for 2 fields and complenymy for 1 field while antonymy doesn't reach this level for any field.

The results of a comparison of the total sums of instances of relations are similar: the sum for hyperonymy is slightly higher than for synonymy and much higher than for other relations. But once again, if hyponymy and hyperonymy are interpreted 
Table 6. Basic semantic relations in non-recurrent chains

\begin{tabular}{|c|c|c|c|c|c|c|c|c|}
\hline \multirow[t]{2}{*}{ Stimulus } & \multicolumn{8}{|c|}{ Number of relations } \\
\hline & syn & ant & compl & hypon & hyper & mer & hol & cohyp \\
\hline \multicolumn{9}{|l|}{ People } \\
\hline woman & $4 / 4$ & $0 / 0$ & $3 / 3$ & $7 / 8$ & $4 / 5$ & $3 / 3$ & $1 / 1$ & $2 / 2$ \\
\hline man & $4 / 4$ & $0 / 0$ & $5 / 6$ & $9 / 10$ & $4 / 5$ & $3 / 3$ & $3 / 3$ & $3 / 3$ \\
\hline girl & $6 / 6$ & $1 / 1$ & $8 / 9$ & $2 / 2$ & $6 / 7$ & $3 / 5$ & $2 / 2$ & $1 / 1$ \\
\hline subtotal & $14 / 14$ & $1 / 1$ & $16 / 18$ & $18 / 20$ & $14 / 17$ & $9 / 11$ & $6 / 6$ & $6 / 6$ \\
\hline \multicolumn{9}{|l|}{ Animals } \\
\hline sheep & $2 / 3$ & $1 / 1$ & $8 / 9$ & $7 / 7$ & $10 / 11$ & $15 / 16$ & $9 / 10$ & $7 / 7$ \\
\hline spider & $5 / 6$ & $0 / 0$ & $0 / 0$ & $4 / 4$ & $7 / 7$ & $4 / 4$ & $4 / 4$ & $8 / 10$ \\
\hline lion & $1 / 2$ & $0 / 0$ & $1 / 1$ & $2 / 2$ & $7 / 9$ & $5 / 7$ & $7 / 7$ & $3 / 6$ \\
\hline subtotal & $8 / 11$ & $1 / 1$ & $9 / 10$ & $13 / 13$ & $24 / 27$ & $24 / 27$ & $20 / 21$ & $18 / 23$ \\
\hline \multicolumn{9}{|l|}{ Tools } \\
\hline needle & $4 / 4$ & $0 / 0$ & $0 / 0$ & $1 / 1$ & $3 / 3$ & $4 / 4$ & $3 / 3$ & $0 / 0$ \\
\hline hammer & $4 / 4$ & $0 / 0$ & $0 / 0$ & $6 / 6$ & $8 / 10$ & $3 / 3$ & $1 / 1$ & $4 / 4$ \\
\hline scissors & $2 / 2$ & $1 / 1$ & $0 / 0$ & $5 / 5$ & $2 / 2$ & $9 / 9$ & $10 / 10$ & $3 / 3$ \\
\hline subtotal & $10 / 10$ & $1 / 1$ & $0 / 0$ & $12 / 12$ & $13 / 15$ & $16 / 16$ & $14 / 14$ & $7 / 7$ \\
\hline \multicolumn{9}{|l|}{ Furniture } \\
\hline table & $0 / 0$ & $0 / 0$ & $0 / 0$ & $10 / 10$ & $5 / 5$ & $3 / 4$ & $3 / 3$ & $5 / 5$ \\
\hline chair & $0 / 0$ & $1 / 1$ & $0 / 0$ & $6 / 6$ & $7 / 7$ & $6 / 8$ & $3 / 3$ & $6 / 7$ \\
\hline bed & $5 / 5$ & $2 / 2$ & $0 / 0$ & $2 / 2$ & $3 / 3$ & $1 / 1$ & $0 / 0$ & $1 / 3$ \\
\hline subtotal & $5 / 5$ & $3 / 3$ & $0 / 0$ & $18 / 18$ & $15 / 15$ & $10 / 13$ & $6 / 6$ & $12 / 15$ \\
\hline \multicolumn{9}{|l|}{ Emotions } \\
\hline anger & $16 / 19$ & $1 / 1$ & $0 / 0$ & $1 / 1$ & $3 / 3$ & $1 / 1$ & $0 / 0$ & $9 / 10$ \\
\hline joy & $6 / 7$ & $3 / 3$ & $0 / 0$ & $3 / 3$ & $2 / 2$ & $1 / 1$ & $1 / 1$ & $7 / 8$ \\
\hline afraid & $22 / 36$ & $1 / 1$ & $0 / 0$ & $2 / 2$ & $0 / 0$ & $0 / 0$ & $0 / 0$ & $0 / 0$ \\
\hline subtotal & $44 / 62$ & $5 / 5$ & $0 / 0$ & $6 / 6$ & $5 / 5$ & $2 / 2$ & $1 / 1$ & $16 / 18$ \\
\hline \multicolumn{9}{|c|}{ Professions } \\
\hline priest & $1 / 1$ & $1 / 1$ & $0 / 0$ & $5 / 5$ & $2 / 2$ & $0 / 0$ & $8 / 9$ & $0 / 0$ \\
\hline soldier & $3 / 3$ & $2 / 2$ & $3 / 3$ & $3 / 3$ & $5 / 5$ & $9 / 10$ & $13 / 13$ & $1 / 1$ \\
\hline king & $4 / 4$ & $0 / 0$ & $1 / 1$ & $2 / 2$ & $4 / 4$ & $3 / 3$ & $4 / 4$ & $0 / 0$ \\
\hline subtotal & $8 / 8$ & $3 / 3$ & $4 / 4$ & $10 / 10$ & $11 / 11$ & $12 / 13$ & $25 / 26$ & $1 / 1$ \\
\hline \multicolumn{9}{|l|}{ Tastes } \\
\hline sweet & $1 / 1$ & $1 / 1$ & $0 / 0$ & $9 / 9$ & $11 / 11$ & $3 / 4$ & $1 / 1$ & $2 / 2$ \\
\hline sour & $3 / 3$ & $0 / 0$ & $1 / 1$ & $3 / 3$ & $7 / 7$ & $5 / 5$ & $3 / 3$ & $5 / 5$ \\
\hline bitter & $4 / 4$ & $5 / 5$ & $0 / 0$ & $8 / 8$ & $12 / 12$ & $3 / 3$ & $3 / 3$ & $6 / 6$ \\
\hline subtotal & $8 / 8$ & $6 / 6$ & $1 / 1$ & $20 / 20$ & $30 / 30$ & $11 / 12$ & $7 / 7$ & $13 / 13$ \\
\hline \multicolumn{9}{|l|}{ Colors } \\
\hline yellow & $5 / 5$ & $1 / 1$ & $1 / 1$ & $3 / 3$ & $5 / 5$ & $2 / 2$ & $1 / 1$ & $2 / 3$ \\
\hline red & $2 / 2$ & $0 / 0$ & $2 / 2$ & $3 / 3$ & $2 / 2$ & $1 / 1$ & $1 / 1$ & $3 / 3$ \\
\hline white & $2 / 2$ & $4 / 4$ & $0 / 0$ & $1 / 1$ & $1 / 2$ & $3 / 3$ & $2 / 2$ & $1 / 1$ \\
\hline subtotal & $9 / 9$ & $5 / 5$ & $3 / 3$ & $7 / 7$ & $8 / 9$ & $6 / 6$ & $4 / 4$ & $6 / 6$ \\
\hline Total: & $106 / 127$ & $25 / 25$ & $33 / 36$ & $104 / 106$ & $120 / 129$ & $90 / 100$ & $83 / 85$ & $79 / 89$ \\
\hline
\end{tabular}


as two complementary aspects of one superordination relation and their instances added up, the total sum of instances for the superordination relation (235) is much higher than the sums for any other relations (also higher than the total for the partwhole relation if instances of meronymy and holonymy are added up). The same applies to the subtotals for most fields (for the superordination relation the subtotals are as follows: People: 37, Animals: 40, Tools: 27, Furniture: 33, Emotions: 11, Professions: 21, Tastes: 50, Colors: 16) except Emotions and Professions (but also except Animals and Tools if instances of meronymy and holonymy are added as instances of the part-whole relation). The differences between superordination and synonymy, antonymy, complenymy and cohyponymy are statistically significant (as measured using the U-test). Only the difference between superordination and part-whole relations does not reach the $5 \%$ significance level.

The relative dominance of the superordination relation and its typicality as a factor determining the structure of different parts of the mental lexicon is even more visible when quasi-hyperonymy and quasi-hyponymy are taken into consideration. The results obtained for these relations are (notations as in previous tables): for quasi-hyponymy $9 / 9$, for quasi-hyperonymy 18/18, therefore 27 instances for the quasi-superordination relation as a whole.

As in the case of recurrent chains, only a few (19) instances of the individual-set relation were found in non-recurrent chains and one instance of converse relation. There are also many instances of attributive relations, especially for the stimuli of the Colors, Tastes and Emotions fields, some instances of function relations (most often for artifacts fields) and of the location relation.

\section{Discussion}

The results of the analysis of the large corpus of 1200 chains obtained in the experiment show that strong connections, manifesting themselves in symmetrical associations between words, are rather typical characteristics of the individual mental lexical structure: chains with recurrent elements make up about $50 \%$ of the corpus and almost all of them are based on direct associations (i.e. they are $\mathrm{ABAB}, \mathrm{ABAC}$ and $\mathrm{ABCB}$ chains). Moreover, the relative commonality of strong, symmetrical associations is characteristic across various parts of the lexicon: recurrent chains are numerous in all 8 semantic fields the stimulus words (S1) belong to.

It turns out that the strongest associative connections in individual lexicons, asserting themselves as the basis of $\mathrm{ABAB}$ chains, are sometimes interpersonally common, i.e. appear as identical chains constructed by different respondents. And, interestingly, no ABCA chains are interpersonally shared while some chains consisting of 4 different elements (i.e. ABCD chains) are. The associative reactivation of a lexical unit by means of two intermediate words or a kind of "indirect circularity" in the associative structure (e.g., evoking the item chair again through 
the mediation of kitchen and table) is a rather individual process or an individual property of the mental lexicon.

A semantic analysis of chains of associations revealed a characteristic and relatively important role of the superordination relation as a factor connecting elements of the mental lexicon, both in circular and non-circular fragments of the lexicon (shown, respectively, by recurrent and non-recurrent chains). In particular semantic fields, some paradigmatic relations are more typical than others. For example, names of emotions are often associatively related through synonymy (e.g., anger $\rightarrow$ wrath, afraid $\rightarrow$ fear) while names of people through the complementary relation (e.g., man $\rightarrow$ woman). But the superordination relation appears more regularly in different fields than other paradigmatic relations, so it can be interpreted as a more universal factor determining the mental lexicon structure.

Moreover, the superordination relation forms the basis of the $\mathrm{ABA}$ parts of $\mathrm{ABAC}$ chains and the $\mathrm{BCB}$ parts of $\mathrm{ABCB}$ chains more often than any other relation does. This domination in evoking "symmetrical" association is rather striking because of the logically asymmetrical or directional nature of superordination (as opposed to synonymy, classical antonymy or complenymy), with its two complementary aspects: hyponymy and hyperonymy. The hypo-/hyperonymic structure is typically a branching one: a hyperonym has two or often more hyponyms (see Cruse, 1995, 2000). Thus, sheep, lion and many other lexical items can be, in theory, equally easily associated with the same hyperonym animal, but, in theory again, each of them can be evoked as a reaction to the stimulus word animal in a free association test and the choice of one of them can be influenced by many factors. It is not a case of antonymy relations (especially complementary antonymy) nor of synonymy (more than two more or less equally common synonyms are rather rare in any natural language; one interesting exception in Polish is the set of synonyms: obawa, lęk, niepokój, strach, trwoga; the closest English equivalents are: afraid, anxiety, apprehension, fear, fright).

Activation of a given hyponym as a reaction to a more general item (its hyperonym) can be interpreted as an effect or as a manifestation of the prototypical structure of the category labeled by the hyperonym in the mental lexicon of a given respondent. This interpretation is consistent with the results concerning $\mathrm{ABAB}$ chains. Seventeen chains of this type (see Table 5) were constructed on the basis of the superordination relation (for example: priest $\rightarrow$ clergyman $\rightarrow$ priest $\rightarrow$ clergyman, table $\rightarrow$ furniture $\rightarrow$ table $\rightarrow$ furniture, man $\rightarrow$ lover $\rightarrow$ man $\rightarrow$ lover $)$ but in the sequence showing $\mathrm{ABAB}$ chains shared by a minimum of 5 respondents (see par. Identical chains) there are no hypo/hyperonymic chains, maybe because of the differences concerning individual category structures (i.e. differences related to the prototypical parts of categories), caused by interpersonal differences in the respondents' experiences.

However, the results obtained in the experiment should not be over-generalized, nor overestimated. They could be biased by the selected input material - the names of some artifacts, living beings, emotions and sensations. The material is not quite 
representative of the lexicon as a whole, not even of the lexicon part consisting of nouns. Nevertheless, the tendency to react rather regularly with hypo/hyperonymic associations to stimuli belonging to different lexical fields (even fields for which other semantic relations, such as complenymy, synonymy etc. are more typical) remains interesting proof of the role of hierarchical organization in the mental representation of reality.

Besides, this kind of experiment, consisting in free association tests connected with one another, offers an insight into some interesting aspects of the structure of the mental lexicon.

\section{References}

Aristotle (1844). Logique d'Aristote. Vol. 1: Catégories - Herméneia. Paris: Librairie de Ladrange.

Berlin, B., Breedlove, D.E., \& Raven, P.H. (1968). Covert categories and folk taxonomies. American Anthropologist, 70, 2, 290-299.

Berlin, B., Breedlove, D.E., \& Raven, P.H. (1973). General principles of classification and nomenclature in folk biology. American Anthropologist, 75, 1, 214-242.

Berlin, B., Breedlove, D.E., \& Raven, P.H. (1974). Principles of Tzeltal plant classification. New York, London: Academic Press.

Bock, J.K. (2002). Meaning, sound, and syntax. Lexical priming in sentence production. In G.T.M. Altmann (Ed.), Psycholinguistics. Critical concepts in psychology. Vol. 5 (pp. 378-404). London, New Jork: Routledge.

Cieślicka-Ratajczak, A. (1995). The mental lexicon in second language learning. Studia Anglica Posnaniensia, 29, 105-117.

Conklin, H.C. (1962). Lexicographical treatment of folk taxonomies. In F.W. Householder \& S. Saporta (Eds.), Problems in lexicography (pp. 119-141). Bloomington: University of Indiana.

Collins, A.M. \& Loftus, E.F. (1975). A spreading-activation theory of semantic processing. Psychological Review, 82, 407-428.

Collins, A.M. \& Quillian, M.R. (1969). Retrieval time from semantic memory. fournal of Verbal Learning and Verbal Behavior, 8, 240-247.

Cruse, D.A. (1995). Lexical semantics. Cambridge: Cambridge University Press.

Cruse, D.A. (2000). Meaning in language. An introduction to semantics and pragmatics. Oxford: Oxford University Press.

Cruse, D.A. (2002). Hyponymy and its varieties. In R. Green, C.A. Bean, \& S.H. Myaeng (Eds.), The semantics of relationships. An interdisciplinary perspective (pp. 3-21). Dordrecht, Boston, London: Kluwer Academic Publishers.

Fellbaum, Ch. (1999). A semantic network of English verbs. In Ch. Fellbaum (Ed.), WordNet. An electronic lexical database (pp. 69-104). Cambridge, MA: MIT Press.

Ferrand, L. (2001). Normes d'associations verbales pour 260 mots „abstraits”. L'Année Psychologique, 101, 4, 683-721. 
Ferrand, L. \& Alario, F.-X. (1998). Normes d'associations verbales pour 366 noms d'objets concrets. L'Année Psychologique, 98, 4, 659-709.

Forster, K.I. (2002). Accessing the mental lexicon. In G.T.M. Altmann (Ed.), Psycholinguistics. Critical concepts in psychology. Vol. 1 (pp. 270-296). London, New York: Routledge.

Harley, T. (2003). The psychology of language. From data to theory. Hove, New York: Psychology Press.

Hirsh, K.W. \& Tree, J.J. (2001). Word association norms for two cohorts of british adults. Fournal of Neurolinguistics, 14, 1, 1-44.

Houde, O. (1990). Logical categorization: schematic knowledge, categorical knowledge, and image versus linguistic format. A study in six- to eleven-year-olds. Cahiers de Psychologie Cognitive, 10, 4, 343-384.

Hörmann, H. (1972). Introduction à la psycholinguistique. Paris: Librairie Larousse. Hunca-Bednarska, A. (1997). Skojarzenia werbalne w schizofrenii (Verbal associations in schizophrenia). Lublin: Czelej.

Johnson, D.E. \& Shean, G.D. 1993. Word associations and schizophrenic symptoms. Journal of Psychiatric Research, 27, 1, 69-77.

Kurcz, I. (1967). Polskie normy powszechności skojarzeń swobodnych na 100 słów z listy Kent-Rosanoffa (The Polish norms for free responses to 100 words from the Kent-Rosanoff word association test). Studia Psychologiczne, 8, 122-255.

Kurcz, I. (1976). Psycholingwistyka (Psycholinguistics). Warszawa: PWN.

Leech, G. (1987). Semantics. The study of meaning. Harmondsworth: Penguin Books. Latour, M.A. \& McKelvie, S.J. (1994). Effects of type of input and type of processing on recall hypermnesia. Revue canadienne de psychologie experimentale, 48, 3, 451-459.

Lyons, J. (1977). Semantics. Vol. 1. Cambridge: Cambridge University Press.

Łobacz, P. \& Mikołajczak-Matyja, N. (2002). Skojarzenia słowne w psycholeksykologii i onomastyce psycholingwistycznej(Verbal associations in psycholexicology and in psycholinguistic onomastics). Poznań: Sorus.

Marslen-Wilson, W., Tyler, L.K., Waksler, R., \& Older, L. (2002). Morphology and meaning in the English mental lexicon. In G.T.M. Altmann (Ed.), Psycholinguistics. Critical concepts in psychology. Vol. 2 (pp. 17-83). London, New York: Routledge.

Medin, D.L. \& Atran, A. (1999). Introduction. In D.L. Medin \& S. Atran (Eds.), Folkbiology (pp. 1-15). Cambridge, MA: MIT Press.

Murphy, M.L. (2003). Semantic relations and the lexicon. Cambridge: Cambridge University Press.

Mikołajczak-Matyja, N. (2004). Skojarzenia słowne niewidomych i widzacych użytkowników języka polskiego - studium porównawcze (Verbal associations of blind and sighted users of the Polish language - a comparative study). Investigationes Linguisticae, 11, 1-17. Retrieved from: www.inveling.amu.edu.pl Mikołajczak-Matyja, N. (2008). Hierarchiczna struktura leksykonu umysłowego. 
Relacje semantyczne w leksykonie widzacych i niewidomych użytkowników języka (The hierarchical structure of the mental lexicon. Semantic relations in the lexicon of sighted and blind language users). Poznań: UAM.

Miller, G.A. \& Johnson-Laird, P.N. (1976). Language and perception. Cambridge: Cambridge University Press.

Moss, H.E., McCormick, S.F., \& Tyler L.K. (2002). The time course of activation of semantic information during spoken word recognition. In: G.T.M. Altmann (Ed.), Psycholinguistics. Critical concepts in psychology. Vol. 2 (pp. 84-119). London, New York: Routledge.

Moss, H.E., Ostrin, R.K.., Tyler, L.K., \& Marslen-Wilson, W.D. (1995). Accessing different types of lexical semantic information: evidence from priming. Fournal of Experimental Psychology: Learning, Memory, and Cognition, 21, 4, 863-883. Pogonowski, J. (1991). Hiponimia (Hyponymy). Poznań: UAM.

Quillian, M.R. (1968). Semantic memory. In M.L. Minsky (Ed.), Semantic information processing (pp. 227-270). Cambridge, MA: MIT Press.

Sowa, J.F. (2000). Knowledge representation. Pacific Grove, Albany, London, Toronto: Brooks/Cole.

Tulving, E. (1972). Episodic and semantic memory. In E. Tulving, \& W. Donaldson (Eds.), Organization of memory (pp. 380-402). New York: Academic Press.

Ungerer, F. \& Schmid, H-J. (1996). An introduction to cognitive linguistics. London, New York: Longman.

Upmanyu, V.V., Bhardwaj, S., \& Singh, S. (1996). Word-association emotional indicators: associations with anxiety, psychoticism, neuroticism, extraversion, and creativity. The fournal of Social Psychology, 136, 4, 521-529.

Vigliocco, G. \& Vinson, D.P. 2007. Semantic representation. In. M.G. Gaskell (Ed.), Psycholinguistics (pp. 195-215). Oxford: Oxford University Press.

Wilks, C. \& Meara, P. (2002). Untangling word webs: graph theory and the notion of density in second language word association networks. Second Language Research, 18, 4, 303-324.

Wolter, B. (2002). Assessing proficiency through word associations: is there still hope? System, 3, 3, 315-329.

Wunderlich, D. (2006). Introduction: What the study of the lexicon is about. In D. Wunderlich (Ed.), Advances in the theory of the lexicon (pp. 1-25). Berlin, New York: Mouton de Gruyter.

Wyver, S.R., Markham, R., \& Hlavacek, S. (2000). Inferences and word associations of children with visual impairments. Journal of Visual Impairment and Blindness, 94, 204-217. 